\title{
Climate change and the food production system: impacts and adaptation in China
}

\author{
Wenbin Wu $\cdot$ Peter H. Verburg $\cdot$ Huajun Tang
}

Received: 10 August 2013/Accepted: 25 August 2013/Published online: 13 September 2013

(C) Springer-Verlag Berlin Heidelberg 2013

China has received a lot of attention from both the scientific and policy community in its ability to maintain selfreliance in food supply (Verburg et al. 2000; Yang and Li 2000; Yu et al. 2012). Advances in technology and changing agronomic practices have been responsible for significant increases in food production in China over past several decades (Xiong et al. 2012). Yet, since the 1980s, the unprecedented growth of both the economy and the population has led to a decrease in the area of cropland (Deng et al. 2006; He et al. 2013). The growing competition for land, water, and energy, and the overexploitation of fisheries, seriously impairs the production of food. Global environmental change, particularly climate change, makes the situation more challenging. Changes in climate may have implications for climate-sensitive systems such as agriculture, forestry, and other natural resources (Wu et al. 2011; Verburg et al. 2013).

China is among the most affected countries by climate change (Ye et al. 2012). Continuous measurements from meteorological stations show that there is a strong warming of China over the past five decades and the temperature has increased by $1.2^{\circ} \mathrm{C}$ since 1960 , which is much higher than

\footnotetext{
W. Wu $\cdot$ H. Tang

Key Laboratory of Agri-Informatics, Ministry of Agriculture of China, Beijing 100081, China

e-mail: wuwenbin@caas.cn

W. Wu $\cdot$ H. Tang $(\bowtie)$

Institute of Agricultural Resources and Regional Planning,

Chinese Academy of Agricultural Sciences,

Beijing 100081, China

e-mail: tanghuahun@caas.cn

P. H. Verburg

Institute for Environmental Studies, VU University Amsterdam, 1081 HV Amsterdam, The Netherlands
}

the overall rate of global surface temperature change (Piao et al. 2010). Although there is no observed significant longterm trend in country-average precipitation since 1960, there are significant regional precipitation trends. The drier regions of northeastern China (including North China and Northeast China) are receiving less and less precipitation in summer and autumn (a $12 \%$ decline since 1960). By contrast, the wetter region of southern China is experiencing more rainfall during both summer and winter. As for future projections, climate models tell us unambiguously that the warming trend will continue, and China's average temperature is estimated to increase further by $1-5{ }^{\circ} \mathrm{C}$ by 2100 . This acceleration in temperature warming and its associated changes in precipitation have affected agriculture and food production in China. One of the greatest challenges for China in the twenty-first century will be to ensure that the food supply sustainably meets the needs of the population despite the necessary adaptations to climate change. Meeting this task will require technical and institutional innovations that increase food production and facilitate adaptation to changing climatic conditions.

Climate change affects agriculture and the food production system in many ways (Godfray et al. 2011). Changes in climatic variables drive changes in overall food production through interacting effects on crop yields and crop areas. Although there has been much research to investigate the impacts of climate change on crop/food production (Barry and Cai 1996; Chen et al. 2013; Li et al. 2011, 2005; Piao et al. 2010; Wang et al. 2009; Zhang and Huang 2012), these studies are generally either focused on a single aspect of the interactions between climate change and food production or are performed in specific small regions. This causes some inconsistency in assessment results of climate change impacts, and well-recognized conclusions are therefore unavailable (Yang et al. 2013). 
For example, some studies suggest that global warming will have an adverse effect on food production, while others indicate that crop yields would benefit from global warming, at least in the early stages, in the temperate midto high-latitude regions (Chen et al. 2011; Lobell et al. 2011; Zhou et al. 2013). At the same time, straightforward assessments of climate change impacts on crop yields by crop growth models ignore the adaptation of farmers to climate change through crop choice and management. Thus, systematic, large-scale, and integrated studies that investigate the interactions between climate change and food production in China are needed.

In response to this, the Ministry of Science and Technology of China launched a 5-year project "Impacts of Climate Change on Food Production Systems in China" through its National Major Scientific Research Program in 2010. This project, coordinated by the Chinese Academy of Agricultural Sciences, is expected to analyze and understand the complex impacts of climate change on China's food production system in a holistic and systematic way. Several important questions will be addressed: What impacts did climate change in the past decades have on the spatiotemporal dynamics of agricultural resources for food production? How do natural disasters, pest and disease, and extreme events occur and evolve over time and space under climate change? How and to what extent may climate change affect the multiple cropping systems, cropping acreage and patterns, crop yields, and eventually the overall food security in China? How can food production adapt to natural disasters and climate warming? Scientific results from this project were already published in a wide range of peer-reviewed journals (e.g., Liu et al. 2012; Xiong et al. 2012; Ye et al. 2012; Yu et al. 2012). This special issue of Regional Environmental Change aims to look at some key issues involved in food production in China under conditions of climate change and to communicate the latest research achievements from this project. One of the seven articles collected in this special issue performs a study for whole China, while the other six articles present researches for the northern part of China as it is thought to be the most susceptible to climate change. Among them, three are specifically focused on Northeast China, two on North China Plain and one on Northwest China.

Xiong et al. present a nationwide empirical study using gridded climate and observed crop yield data to analyze the effects of observed warming trends since 1980 on crop yields for the four main staple crops (rice, wheat, maize, and soybean) in China. Based on this analysis, the authors identify the areas in China where food production is susceptible to increased temperature. The results show that there are clear negative yield responses of maize, wheat, and soybean to increased growing-season temperature at national scale. At the regional scale, over $50 \%$ of the arable land exhibited yield susceptibility to past warming trends, with maize showing the highest vulnerability and rice the lowest vulnerability. Regarding the warming-risk areas for food production, a total of $52.6 \%$ of the arable land in China showed yield decrease for at least one crop, indicating the possible warming susceptibility in these areas. The Loess Plateau is identified as the most vulnerable region to the past warming for food production in China due to its largest proportion of vulnerable planting area and substantial decrease in yields for many crops. The finer resolution analysis of the temperature-yield relationships in this study has importantly highlighted the potential warming-risk areas for food production and indicated the hotspots for prioritizing adaptation strategies for future climate change in China.

Zhao et al. analyze the variability of available climate resources (including heat, precipitation, and sunshine duration) and agro-meteorological disaster risks during the entire growing season in sensitive cropping areas in Northeast China. The sensitive cropping areas were defined as those where the maize maturity types shifted due to climate warming. The historical climate data from 74 meteorological stations for 1951-2010 and crop data from 47 agro-meteorological stations for 1981-2007 were used in this article. It is found that there are larger middle- and late-maturity-type cropping areas during the second period (1981-2010) than during the first period (1951-1980). The area planted with early maturity maize tended to decrease in the northwestern part of the study area. In sensitive cropping areas, growing degree days increased by 2.8-11.5\%, and the northern part showed higher increasing amplitude than the southern part. Both accumulated precipitation and sunshine duration during the maizegrowing season showed a significant increasing trend in the north, but a significant decreasing trend in the south. The maturity-type shifts in spring maize caused more exposure to chilling damage and water deficiency in the sensitive cropping areas. The article demonstrates the importance of taking full account of disaster risks when changing crop variety with different maturity types is taken as one of the effective ways for agricultural production to adapt to climate change.

Zhang et al. introduce a new heat deficit index (i.e., accumulated deficit temperature unit, $\mathrm{ADU}_{\mathrm{n}-}$ ) and utilize it to depict the responses of rice yield to climate change in the northeastern three provinces of China. They conduct correlation and regression analyses of the climate records of 79 meteorological stations and records of rice yields from the years 1960 to 2009. Several climatic variables, including the monthly mean, anomalies in the minimum and maximum temperatures during the rice-growing season, and the accumulated deficit temperature unit, were used to fit the rice yield anomalies. It is indicated that rice 
yield in Northeast China is more affected by monthly anomalies in $\mathrm{ADU}_{\mathrm{n}-}$ during the growing season than by those in the monthly averages of climatic variables. The $\mathrm{ADU}_{\mathrm{n}-}$ index is able to explain about $54.1 \%$ of the variability in rice yield average of the three provinces. The authors also analyze the rice yield response to climate change in the years 2020-2040 under future climate change scenarios. Rice production in Northeast China benefits form future warming and increases by approximately $1.7 \%$ above the present yield. The findings of this article can help policy makers and crop producers to take proper adaptation measures even when exposed to the global warming situation in Northeast China.

$\mathrm{Li}$ et al. present an empirical study for the same region of Northeast China, but choose another perspective. They analyze the crop response and adaption to climate change through investigating the temporal changes in crop phenology. This study combines the observed climatic and maize phenological data from 53 agricultural meteorological stations in Northeast China between 1990 and 2012 to analyze the spatiotemporal changes in maize phenology and temperatures, as well as their correlation in major maize-growing areas of Northeast China. The results show that the seedling and heading dates advance significantly at 22 out of the 53 stations, while the maturity dates delay significantly at 23 stations during the period of 1990-2012. The growing period (GP), the vegetative growing period (VGP), and the reproductive growing period (RGP) increase significantly at $30 \%$ of the investigated stations. A positive correlation is found between GP length and $T_{\text {mean }}$ at 40 stations. Both negative and positive correlations are found between VGP and $T_{\text {mean }}$, while RGP length is significantly and positively correlated with $T_{\text {mean }}$. This study shows that agronomic factors greatly contribute to the shift in maize phenology and most farmers had already responded to climate change by actively adopting longer season cultivars. This study demonstrates that phenology adjustment should be necessarily included in enacting the adaptation strategies in response to climate change.

El Niño-Southern Oscillation (ENSO) significantly contributes to climate anomalies, especially to global and regional rainfall. Liu et al. analyze the impacts of ENSO episodes on local climate and crop yields of winter wheat and summer maize in North China Plain. Data on daily temperature, precipitation, and sunshine hours for 50 years (1956-2006) were used to build climate scenarios for three categories of ENSO: years with El Niño events, years with La Niña events, and neutral years. Precipitation decreased and temperature and sunshine hours increased in both El Niño and La Niña years, but remained stable in neutral years. The agricultural production systems simulator model (APSIM) is then used to investigate the impacts of ENSO phases on crop yields under rain fed and irrigated managements at three representative sites. Under full irrigation, the crop yields are not significantly affected, although the yields in both El Niño and La Niña years differ markedly from those in neutral years. However, under rain-fed conditions, the yield of maize decreases greatly, the reduction being the highest in La Niña years at all the sites. The authors conclude that El Niño and La Niña have similar effects on climatic variables and crop yields across the North China Plain: low yields in El Niño and La Niña years due to lower precipitation and high yields in neutral years due to longer sunshine hours and additional irrigation.

Yang et al. conduct a study to analyze the separate and interacting effects of future changes in $\mathrm{CO}_{2}$, temperature, and precipitation on the growth and yield of winter wheat in five representative sites on the North China Plain. They collect daily maximum and minimum temperatures and precipitation data from the Model for Interdisciplinary Research On Climate (MIROC), based on the scenario A1B for 2085-2100. A novel statistical algorithm is proposed to calibrate these MIROC climate data, which are then used by the Environmental Policy Integrated Climate (EPIC) model, to assess their separate and interacting effects on winter wheat yield. Results indicate that an increase in $\mathrm{CO}_{2}$ concentration of up to $680 \mathrm{ppm}$ would increase the yield by 24.8 and $43.1 \%$ in irrigated and rainfed fields, respectively. Increases in the average maximum and minimum temperature would increase the crop yield by $5.2 \%$ in irrigated condition, but decrease it by $7.2 \%$ in rain-fed condition. However, the yield of irrigated fields decreased by $5.5 \%$ when the annual precipitation increased by $317 \mathrm{~mm}$, whereas that of rain-fed fields increased by $30.1 \%$. With a constant $\mathrm{CO}_{2}$ level, temperature and precipitation decrease the yield by -0.9 and $-1.9 \%$ for irrigated and rain-fed fields, respectively. When the $\mathrm{CO}_{2}$ level increases to $680 \mathrm{ppm}$, the interacting effect of elevated $\mathrm{CO}_{2}$, temperature, and precipitation increases the average yield by $23.1 \%$ with the irrigated treatment and by $27.7 \%$ with the rain-fed treatment. The findings on separate and interacting effects of climate change on crop yields in this article provide useful information for identifying appropriate management or genotype adaptations of winter wheat to cope with climate change in North China Plain.

Zuo et al. contribute a different study to understand the relationship between cropland transition and climate change in the arid and semiarid region of Northwest China. Time series of remote sensing data for the late 1980s, 1995, 2000, 2005, 2008, and 2010 are used to clarify the change intensity and conversion pattern of cropland to identify the effects of a series of governmental policies and their influence on the climate system. They combine a transition matrix model, a dynamic degree model, an area-weighted 
centroid model and area percentages to analyze the temporal change in cropland. During the period from the late 1980 s to 2010 , cropland increased dramatically by $23,182.17 \mathrm{~km}^{2}$, an increase of $13.61 \%$ relative to the area under cultivation in the late 1980s. They find that cropland transition mainly accumulates in the western oasis-desert ecotone of the study area, while it declines in eastern farming-pastoral ecotone, leading to a westward movement of the cropland centroid. Both conversion of natural vegetation and conversion of unused land result in a net increase in cropland, while the conversion to built-up land leads to a loss of cropland. Population growth, economic development, and land-use management governed by the Grain for Green Program are found to be the three major driving forces of cropland transition. The effect of cropland transition on the climate system is complicated, as different kinds of conversion have different effects on the biogeophysical and biogeochemistry processes that directly affect the local and global climate system.

These seven articles in this special issue present different views on interactions between climate change and food production in China at national and regional scales. While some studies are mainly focused on analyzing the impacts on climate change on crop production, others are focused on the response and adaptation of crop cultivation to climate change. The three major cereal crops (rice, wheat, and maize) are fully covered by these studies. The findings enrich our current knowledge and understanding on recent climate trends, impacts of these trends on food production in China. The results provide helpful insights to assist the development of effective adaptation measures as well as the more targeted improvement of current adaptation practices to climate change in China. These adaptation options can involve improved varieties/species, altering the timing of cropping activities, improving the effectiveness of natural disaster control, adjusting the water and soil management practices, and investing in fertilizer rates and irrigation. All these can help to fully exploit the positive effects of global warming on food production while mitigating its negative impacts.

The studies presented in this issue also demonstrate that the interactions between climate change and food production are a complex issue that requires a multi-dimensional perspective and spatially and temporally explicit analysis. An interdisciplinary and cross-scale approach is thus needed. This requires a further collaboration between the social and natural sciences addressing food production, as well as a breaking down of barriers between the different disciplines and fields of analysis (Godfray et al. 2010; Verburg et al. 2013).

Acknowledgments The papers gathered in this special issue originate from an International Conference on Climate Change and Food
Security, organized in Beijing in November 2011, funded by grants from the National Basic Research Program of China (973 Program) (Grant No. 2010CB951500) and the National Natural Science Foundation of China (Grant Nos. 40930101 and 41271112). This work contributes to the Global Land Project (http://www.globallandproject. org).

\section{References}

Barry S, Cai Y (1996) Climate change and agriculture in China. Glob Environ Change 6:205-214

Chen C, Lei C, Deng A, Dian C, Hoogmoed W, Zhang W (2011) Will higher minimum temperatures increase corn production in northeast China? An analysis of historical data over 1965-2008. Agric For Meteorol 151:1580-1588

Chen Y, Wu Z, Okamoto K, Han X, Ma G, Chien H, Zhao J (2013) The impacts of climate change on crops in China: a Ricardian analysis. Glob Planet Change 104:61-74

Deng X, Huang J, Rozelle S, Uchida E (2006) Cultivated land conversion and potential agricultural productivity in China. Land Use Policy 23:372-384

Godfray HCJ, Beddington JR, Crute IR, Haddad L, Lawrence D, Muir JF, Pretty J, Robinson S, Thomas SM, Toulmin C (2010) Food security: the challenge of feeding 9 billion people. Science 327:812-818

Godfray HCJ, Pretty J, Thomas SM, Warham EJ, Beddington JR (2011) Linking policy on climate and food. Science 331:1013-1014

He J, Liu Y, Yu Y, Tang W, Xiang W, Liu D (2013) A counterfactual scenario simulation approach for assessing the impact of farmland preservation policies on urban sprawl and food security in a major grain-producing area of China. Appl Geogr 37:127-138

Li Y, Conway D, Xiong W, Gao Q, Wu Y, Wan Y, Li Y, Zhang S (2011) Effects of climate variability and change on Chinese agriculture: a review. Clim Res 50:83-102

Li Z, Yang P, Tang H, Wu W, Yin H, Liu Z, Zhang L (2013) Response of maize phenology to climate warming in Northeast China between 1990 and 2012. Reg Environ Change. doi:10. 1007/s10113-013-0503-x

Lin E, Xiong W, Ju H, Xu Y, Li Y, Bai L, Xie L (2005) Climate change impacts on crop yield and quality with $\mathrm{CO}_{2}$ fertilization in China. Philos Trans R Soc B 360:2149-2154

Liu Z, Yang X, Hubbard KG, Lin X (2012) Maize potential yields and yield gaps in the changing climate of northeast China. Glob Change Biol 18:3224-3454

Liu Y, Yang X, Wang E, Xue C (2013) Climate and crop yields impacted by ENSO episodes on the North China Plain:1956-2006. Reg Environ Change. doi:10.1007/s10113013-0455-1

Lobell DB, Schlenker W, Justin CR (2011) Climate trends and global crop production since 1980. Science 333:616-620

Piao S, Ciais P, Huang Y, Shen Z, Peng S, Li J, Zhou L, Liu H, Ma Y, Ding Y, Friedlingstein P, Liu C, Tan K, Yu Y, Zhang T, Fang J (2010) The impacts of climate change on water resources and agriculture in China. Nature 467:43-51

Verburg PH, Chen Y, Veldkamp T (2000) Spatial explorations of land-use change and grain production in China. Agric Ecosyst Environ 82:333-354

Verburg PH, Mertz O, Erb KH, Haberl H, Wu W (2013) Land system change and food security: towards multi-scale land system solutions. Curr Opin Environ Sustain. doi:10.1016/j.cosust.2013. 07.003

Wang J, Mendelsohnb R, Dinarc A, Huang J, Rozellee S, Zhang L (2009) The impact of climate change on China's agriculture. Agric Econs 40:323-337 
Wu W, Yang P, Tang H, You L, Zhou Q, Chen Z, Shibasaki R (2011) Global-scale assessment of potential future risks of food insecurity. J Risk Res 14:1143-1160

Xiong W, Holman IP, Lin E, Conway D, Li Y, Wu W (2012) Untangling relative contributions of recent climate and $\mathrm{CO}_{2}$ trends to national cereal production in China. Environ Res Lett. doi:10.1088/1748-9326/7/4/044014

Xiong W, Holman IP, You L, Yang J, Wu W (2013) Impacts of observed growing-season warming trends since 1980 on crop yields in China. Reg Environ Change. doi:10.1007/s10113-0130418-6

Yang H, Li X (2000) Cultivated land and food supply in China. Land Use Policy 17:73-88

Yang P, Wu W, Li Z, Yu Q, Inatsu M, Liu Z, Tang P, Zha Y, Kimoto M, Tang H (2013) Simulated impact of elevated $\mathrm{CO}_{2}$, temperature, and precipitation on the winter wheat yield in the North China Plain. Reg Environ Change. doi:10.1007/s10113-0130484-9

Ye L, Xiong W, Li Z, Yang P, Wu W, Yang G, Fu Y, Zou J, Chen Z, van Ranst E, Tang H (2012) Climate change impact on China food security in 2050. Agron Sustain Dev. doi:10.1007/s13593012-0102-0

Yu Q, Wu W, Yang P, Li Z, Xiong W, Tang H (2012) Proposing an interdisciplinary and cross-scale framework for global change and food security researches. Agric Ecosyst Environ 156:57-71

Zhang T, Huang Y (2012) Impacts of climate change and inter-annual variability on cereal crops in China from 1980 to 2008. J Sci Food Agric 92:1643-1652

Zhao J, Yang X, Lv S, Liu Z, Wang J (2013) Variability of available climate resources and disaster risks for different maturity types of spring maize in Northeast China. Reg Environ Change. doi:10.1007/s10113-013-0476-9

Zhou Y, Li N, Dong G, Wu W (2013) Impact assessment of recent climate change on rice yields in the Heilongjiang reclamation area of north-east China. J Sci Food Agric. doi:10.1002/jsfa.6087

Zuo L, Zhang Z, Zhao X, Wang X, Wu W, Yi L, Liu F (2013) Multitemporal analysis of cropland transition in a climatesensitive area: a case study of the arid and semiarid region of northwest China. Reg Environ Change. doi:10.1007/s10113-0130435-5 